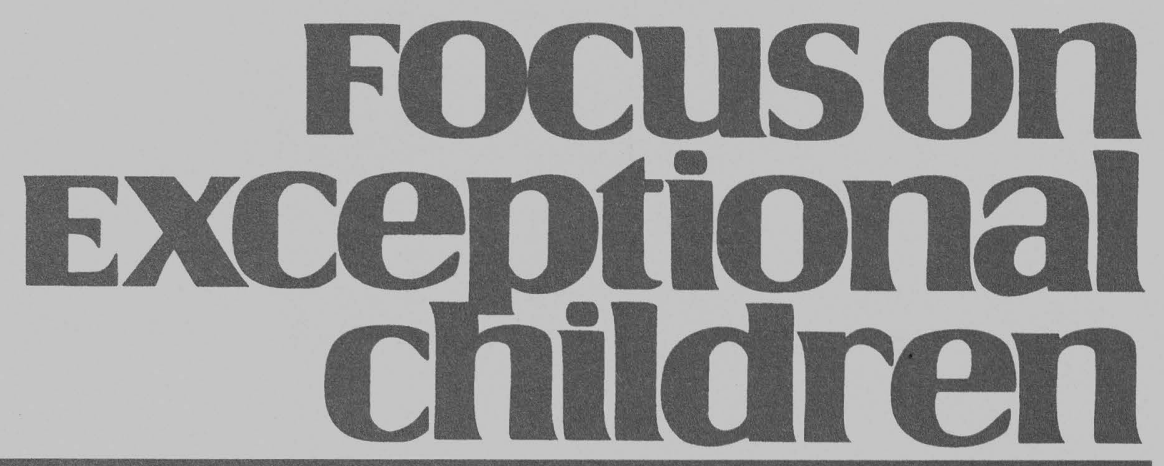

\title{
Effective Practices for Students With Asperger Syndrome
}

\author{
Brenda Smith Myles and Richard L. Simpson
}

During the past several years, recognition and use of the clinical term Asperger Syndrome have increased dramatically. Thus, although this condition was introduced in 1944, Asperger Syndrome (AS) was virtually unknown worldwide until only recently. Today AS is a relatively common developmental disability whose impact on children, families, educators and other professionals is profound (Barnhill, 2001b).

Hans Asperger, a Viennese physician first brought this condition to the attention of the psychiatric community. Based on his work with a group of children with a set of significant and chronic neurodevelopmental social behaviors, Asperger wrote a thesis wherein he described a group of children who today are known diagnostically by his name (Asperger, 1944). Asperger's seminal work accentuated the social peculiarities and social isolation of the children he studied. Although he observed that these individuals had many characteristics in common with children with autism, AS children generally had average cognitive and language development. Based on these characteristics, Asperger opined that his sample represented an independent and distinct clinical condition.

In 1981, Wing resurrected the banner that brought AS to the attention of clinical professionals in a paper in which she discussed the syndrome based on her work with 35 individuals ranging in age from 5 to 35 years. Recognition and wide-scale acceptance of the term AS was further advanced in 1994 when the American Psychiatric Association added the syndrome to its list of pervasive developmental disorders in the Diagnostic and Statistical Manual of Mental Disorders (4th edition) (American Psychiatric Association, 1994).

Today, the condition is widely known and discussed throughout the world, by professionals, parents, and others, but there is intense debate related to whether AS is an independent diagnostic category or is an element of the autism spectrum or continuum (Klin, Volkmar, \& Sparrow, 2000). The pervasive and potent attention to AS is attributable at least in part to its increased prevalence (Ehlers \& Gillberg, 1993). Indeed, ever-growing numbers of individuals are thought to have AS. Kadesjo, Gillberg, and Nagberg (1999), for instance, estimated that as many as 48 per 10,000 children could have the syndrome. These estimates, however, are widely debated and disputed, as represented by Volkmar and Klin's (2000) contention that "the present data are, at best, 'guestimates' of its prevalence"

Brenda Smith Myles is an Associate Professor in the Department of Special Education at the University of Kansas. Richard L. Simpson is a Professor in the Department of Special Education at the University of Kansas. 
(p. 62). Indeed, the most recent edition of the Diagnostic and Statistical Manual of Mental Disorders (4th Edition, Text Revision) (DSM-IV-TR; American Psychiatric Association, 2000), does not give a prevalence estimate for AS, noting that "definitive data regarding the prevalence of Asperger Syndrome are lacking" (p. 82).

Accompanying the increased interest and recognition of AS is the awareness that much remains to be learned about this disorder. Educators and educationally based related services professionals in particular have been challenged to craft and implement appropriate and effective practices, supports, and interventions for students identified as having AS in the absence of a clear understanding of the disorder and without clear direction as to the most suitable educational and other methods. In this connection, this article discusses characteristics of AS-especially those germane to educators-and methods most appropriate for supporting and enhancing the educational experiences of children and youth with AS.

\section{FOCuson
Exceptional
children}

ISSN 0015-511X

FOCUS ON EXCEPTIONAL CHILDREN (USPS 203-360) is published monthly except June, July, and August as a service to teachers, special educators, curriculum specialists, administrators, and those concerned with the special education of exceptional children. This publication is annotated and indexed by the ERIC Clearinghouse on Handicapped and Gifted children for publication in the monthly Current Index to Journals in Education (CIJE) and the quarterly index, Exceptional Children Education Resources (ECER). The full text of Focus on Exceptional Children is also available in the electronic versions of the Education Index. It is also available in microfilm from Xerox University Microfilms, Ann Arbor, MI. Subscription rates: Individual, \$36 per year; institutions, \$48 per year. Copyright (C) 2001, Love Publishing Company. All rights reserved. Reproduction in whole or part without written permission is prohibited. Printed in the United States of America. Periodical postage is paid at Denver, Colorado. POSTMASTER: Send address changes to:

$$
\begin{gathered}
\text { Love Publishing Company } \\
\text { Executive and Editorial Office } \\
\text { P.O. Box } 22353 \\
\text { Denver, Colorado } 80222 \\
\text { Telephone (303) 221-7333 }
\end{gathered}
$$

Karen Harris

University of Maryland
Thomas Skrtic University of Kansas
James Shriner

University of Illinois
Erica J. Lawrence Editor
Stanley F. Love

Publisher

\section{CHARACTERISTICS OF ASPERGER SYNDROME}

Nonschool professionals usually diagnose students with AS. Clinicians, including psychiatrists, clinical psychologists, and related professionals typically provide a diagnosis of Asperger Syndrome based on criteria provided in the DSM-IV-TR (American Psychiatric Association, 2000). This important resource guides the diagnostic process and also provides a cursory understanding of the disorder and the behaviors that correlate with its diagnosis.

Teachers, counselors, school psychologists, and related services professionals are advised to be familiar with DSM$I V$-TR. Yet, as important as it is, educators must keep in mind that this resource fails to provide an understanding of the salient elements of AS that most directly relate to and affect school performance. Accordingly, school professionals must understand and have working knowledge of the school-related social, behavioral/emotional, intellectual/ cognitive, academic, sensory, and motor characteristics of students with AS so they can effectively meet these students' complex and variable school, home, and community needs.

\section{Social Characteristics of Students With Asperger Syndrome}

As originally noted by Asperger (1944) and confirmed by others (Frith, 1991; Myles \& Adreon, 2001; Szatmari, 1991), AS is first and foremost a social disorder. In this connection, Barnhill et al. (2001b) observed that "children with AS are not only socially isolated but also demonstrate an abnormal range or type of social interaction that cannot be explained by other factors such as shyness, short attention span, aggressive behavior, or lack of experience in a given area" (p. 261).

In contrast to most other children on the autism spectrum, individuals with AS are notable for their lack of motivation to interact with others. Their social difficulties, however, frequently stem from an ineptitude and lack of knowledge and skill in initiating and responding in various situations and under variable conditions. For instance, an adolescent with AS may appear odd because of his continuous insistence on sharing with peers an obsessive interest in vacuum cleaners, despite their displays of apathy or abhorrence for this topic.

That the social difficulties of persons with AS may range from social withdrawal and detachment to unskilled social activeness is well documented (Church, Alisanski, \& Amanullah, 2000; Myles \& Simpson, 2001a). Nevertheless, even within this broad range, children and youth with AS are thought to be socially stiff, socially awkward, emotionally blunted, self-centered, and inflexible, and to have difficulty in understanding nonverbal social cues. Preliminary evidence 


\section{DSM-IV-TR DIAGNOSTIC CRITERIA FOR ASPERGER SYNDROME}

A. Qualitative impairment in social interaction, as shown by a minimum of two of the following:

1. Significant impairment in use of nonverbal behavior, such as social interaction gestures, facial expression, eye-to-eye contact, and body postures.

2. Inability to form and maintain developmentally appropriate relationships with peers.

3. Failure to spontaneously seek out others for interactions, such as by sharing interests, achievements, and so forth.

4. Difficulty with social or emotional reciprocity.

B. Repetitive and restricted stereotyped patterns of behavior, activities, and interests, as shown by at least one of the following:

1. Significant preoccupation with one or more stereotyped and restricted interests whose focus or intensity makes it abnormal.

2. Significant manifestation of nonfunctional routines or inflexible adherence to rituals.

3. Repetitive and stereotyped motor movements such as complex whole-body movements, or hand or finger flapping or twisting.

4. Significant and persistent preoccupation with parts of objects.

C. Clinically significant social, occupational, or other functioning impairment.

D. Absence of a clinically significant general language delay.

E. Absence of a clinically significant delay in cognitive development or in development of age-appropriate adaptive behavior (other than social interaction), self-help skills, and childhood curiosity about the environment.

F. Failure to meet diagnostic criteria for schizophrenia or another types of pervasive developmental disorders.

suggests that individuals with AS may be able to infer the meaning of facial expressions as well as match events with facial expression; however, the difficulty arises "when dealing with the simultaneous presentation of facial, voice, body, and situational cues (Koning \& McGill-Evans, 2001, p. 32). Therefore, even when children and adolescents with AS actively try to seek out others, they encounter social isolation because of their lack of understanding of the rules of social behavior, including eye contact, proximity to others, gestures, posture, and so forth (Myles \& Southwick, 1999).

Students with AS often are able to engage in routine social interactions (e.g., basic greetings) without being able to engage in extended interactions or reciprocal conversations. Families and peers often describe children and youth with AS as lacking an awareness of social standards and protocol, lacking common sense, tending to misinterpret subtle social prompts, cues, and unspoken messages, and displaying a variety of socially unaccepted habits and behaviors (Gagnon \& Myles, 1999).

Students with AS also typically display emotional vulnerability and stress (Barnhill, 2001a; Myles \& Adreon, 2001). For instance, students with AS may become upset if they think others are invading their space or when they are in unpredictable and novel social situations. In contrast to most of their peers, however, many children with AS do not reveal stress through voice tone, overt agitation, and so forth. As a result, they may escalate to a point of crisis because of others' unawareness of their excitement or discomfort along with their own inability to predict, control, and manage uncomfortable situations (Myles \& Southwick, 1999). From this description, it also should be obvious that children and youth with AS are relatively easy targets for students who are prone to teasing and bullying others.

While they are known by others for their lack of social awareness, many students with AS themselves are aware that they are different from their peers. As a result, problems with self-esteem and self-concept are common in individuals with AS. These problems often are particularly significant during adolescence and young adulthood (Myles \& Adreon, 2001).

Variable social situations make it difficult for students with AS to apply social rules in a rigid and consistent way. Social rules vary with circumstances; there are no inflexible and universal social conventions and rules. This lack of social consistency is especially confusing for children with AS. They often painfully discover that interactions that may be tolerated or even reinforced in one setting are rejected or punished in others (Myles \& Simpson, 2001a). For example, one third grader with AS could not understand why his calling Mr. Potts, his teacher, "Mr. Poopy-Head" and "Mr. Potty" in unsupervised settings such as the restroom was the source of great delight to his peers, while saying this in the classroom, in the presence of Mr. Potts, drew a much different response.

Children and youth with AS do not acquire greater social awareness and skill merely as a function of age. Rather, students are required to use increasingly sophisticated social skills and to interpret ever more subtle social nuances as they progress through school. Accordingly, individuals 
diagnosed with AS may find themselves more and more in conflict with prevailing social norms as they move through adolescence and young adulthood. As a result of these requirements, and the experiences that follow, individuals with AS are vulnerable to developing a variety of problems.

For instance, studies of adolescents diagnosed with AS indicated that they often experience increased discomfort and anxiety in social situations along with a continuing inability to effectively interact with peers (Cesaroni \& Gar- ber, 1991; Ghaziuddin, Weidmer-Mikhail, \& Ghaziuddin, 1998). Depression and anxiety may also appear at this time (Wing, 1981). Clinical reports have revealed that adolescents and young adults with AS seem to be at higher risk for depression than others (Barnhill, 2001a; Ghaziuddin et al., 1998).

\section{Behavioral and Emotional Characteristics of Students With Asperger Syndrome}

Based on the information presented, it should come as no surprise that children and youth diagnosed with AS often have behavioral and emotional problems. These challenges are most often connected to social deficits associated with the disorder, as, for instance, when a child fails to take her turn in a playground game because she doesn't understand the social rules or protocol of an activity.

Moreover, these problems and challenges frequently involve feelings of stress or loss of control or inability to predict outcomes (Myles \& Southwick, 1999). Thus, students with AS typically have behavior problems connected to their inability to function in a world they see as unpredictable and threatening. Hence, there is little support for Asperger's (1944) original description of children with AS as mean-spirited and malicious. That is, when persons with AS do have behavioral difficulties, their problems are most often associated with their social ineptness, an obsessive interest in a particular topic or theme, a defensive panic reaction, and so forth.

In one of the few studies that attempted to identify the nature of behavior problems and adaptive behavior in students with AS, Barnhill et al. (2000b) compared behavior rating scale inventories completed by parents, teachers, and students. The results revealed that parents had significantly greater concern about the behavior and social skills of their children than did the students' teachers. The responses also showed that parents perceived their children to have significant deficits and weaknesses in a variety of socially related areas, including overall behavior, such as conduct problems, aggression, and hyperactivity, as well as internalizing problems such as withdrawal. Teachers, on the other hand, perceived the children and youth in the study to have both fewer and less significant deficits than did parents, although the teachers did view the students to be "at-risk" in the areas of anxiety, depression, attention problems, and withdrawal. Students' self-evaluations revealed that they did not perceive themselves to have significant problems or to be atrisk on any of the clinical areas measured by the scale.

\section{Intellectual and Cognitive Characteristics of Students With Asperger Syndrome}

A defining feature of AS is that individuals with the disorder generally experience normal intellectual and language development (American Psychiatric Association, 2000). Given the diagnostic and educational importance of this variable, however, surprisingly little is known about the cognitive abilities of students diagnosed with AS. Some researchers have reported an uneven cognitive profile pattern on individualized IQ tests such as the Wechsler intelligence scales (Wechsler, 1989, 1991) in individuals with high-functioning autism, including a significantly higher Performance IQ when compared to Verbal IQ scores (Ehlers et al., 1997; Lincoln, Courchesne, Kilman, Elmasian, \& Allen, 1988). Individuals with high-functioning autism specifically obtained their highest scores on the Block Design subtest and their lowest scores on the Comprehension subtest of the Wechsler scales. Based on their Block Design performance, some have inferred that students with high-functioning autism and AS have relative strength on nonverbal concept-formation tasks, specifically those that require perceptual organization, spatial visualization, abstract conceptualization, and general intelligence (Ehlers et al., 1997).

In contrast, and not surprisingly, relatively poor performance has been reported in areas requiring an understanding of social mores and interpersonal situations, social judgment, common sense, and grasp of social conventionality. Because of limited research on subjects with AS, much of what is assumed about their intellectual abilities is based on inferences from studies of individuals with high-functioning autism.

In one of the few studies of cognitive abilities of children and youth with AS, Barnhill, Hagiwara, Myles, and Simpson (2000) assessed the cognitive profiles of 37 children and youth with AS, as measured by the Wechsler scales (Wechsler, 1989, 1991). The scores generally fell within the average range of abilities, although the IQs ranged from intellectually deficient to superior. The Verbal IQ and Performance IQ scores showed no significant differences.

Consistent with the findings of others, the study did reveal relatively high Block Design subtest scores. These findings suggest generally strong nonverbal reasoning ability and visual-motor spatial integration skill. The Coding subtest revealed relatively low scores, suggesting that many of the subjects had visual-motor coordination difficulties, were distractible, were disinterested in school-related tasks, 
and had visual memory weakness. The students also obtained relatively low scores on the Comprehension subtest, suggesting poor social judgment. This and other studies on this topic, however, have generally failed to identify a specific cognitive profile for individuals diagnosed with AS.

\section{Academic Characteristics of Students With Asperger Syndrome}

The vast majority of students with AS receive their educational experiences predominantly in general education classrooms. General education teachers thus are primarily responsible for the education of these students, albeit frequently with the support of special educators and related service staff.

In many ways, students diagnosed with AS are well qualified to benefit from general classroom experiences. They typically have average intellectual abilities, many are motivated to be with their general education peers, and often these individuals have good rote memory skills and other assets that bode well for their educational success. All too frequently, however, students with AS have significant problems in academic performance, and a number of these students are thought to have learning disabilities (Frith, 1991; Siegel, Minshew \& Goldstein, 1996). The reasons for these problems often are related to the social and communication deficits connected to the disorder.

Moreover, these students' obsessive and narrowly defined interests, concrete and literal thinking styles, inflexibility, poor problem-solving skills, poor organizational skills, and difficulty in discerning relevant from irrelevant stimuli often make it difficult for them to benefit from general education curricula and instructional systems without support and accommodations. Further, they frequently have trouble generalizing knowledge and skills, and students with AS often have difficulty attending to salient curricular cues. With suitable support, however, most students with AS can be successful in school, and a number of these individuals are able to attend college and enjoy a variety of successful careers.

Students with AS, in general, are thought to have particular difficulty in comprehending abstract materials (e.g., metaphors, and idioms); understanding inferentially based materials; and applying skills and knowledge to solve problems. Strengths of children and youth diagnosed with AS tend to be in comprehension of factual material (Church et al., 2000).

A study of academic achievement undertaken by Griswold, Barnhill, Myles, Hagiwara, and Simpson (in press) revealed that while students' mean academic achievement scores were within the average range, their scores ranged from significantly below average to significantly above average. Their strengths generally were in the areas of oral expression and reading recognition. Students who participated in the study revealed relative weakness in comprehending verbally presented information. Their written language scores also were significantly lower than their oral expression scores.

Their mathematics scores were low, too, especially in solving equations and answering mathematical calculation problems. Finally, students who participated in the study had significant difficulties in the areas of problem solving and language-based critical thinking. Predictably, this study reported that in spite of being highly verbal, students with AS had significant difficulties in understanding the orally presented messages of others and arriving at logical solutions to routine and real-life problems.

Many teachers fail to recognize the special academic needs of children and adolescents with AS because these students often give the impression that they understand more than they do (Myles \& Simpson, 2001b). Thus, their pedantic style, seemingly advanced vocabulary, parrot-like responses, and ability to word-call without having the higher-order thinking and comprehension skills to understand what they read may actually mask the deficits of some students with AS.

\section{Sensory Characteristics of Students With Asperger Syndrome}

In his original study of children with AS, Asperger (1944) observed that his subjects had peculiar responses to sensory stimuli. Today this pattern continues, and just as was the case with Hans Asperger, teachers and parents who interact with students who have AS often observe atypical sensory responses (American Psychiatric Association, 2000; Myles, Cook, Miller, Rinner, \& Robbins, 2000). For example, students with AS sometimes are hypersensitive to certain visual stimuli, such as fluorescent lights, and certain sounds, such as the echoing noises in a gym with playing children. This sensitivity can cause agitation and behavior problems.

In a related fashion, some individuals with AS have been reported to have a high tolerance for physical pain. Further, students with AS commonly engage in self-stimulatory responses (e.g., obsessive object spinning, light filtering) and other unusual stereotyped patterns of behavior. These behaviors are most often displayed when the students are under stress or when they experience fatigue, sensory overload, and so forth. The sensory issues of children and youth with AS appear similar to individuals with autism; however, their reactions to sensory issues seem more overt than those seen in individuals with autism (Rinner, 2000).

Dunn, Myles, and Orr (in press) conducted one of the few studies on sensory issues with individuals who have AS. The 
vast majority of children and youth with AS who participated in the study had impairments in the following areas: (a) low/endurance tone, (b) oral sensory sensitivity, (c) inattention/distractibility, (d) poor registration, (e) sedentary, and (f) emotional reactive. More than $75 \%$ of the students demonstrated behavioral problems when sensory issues were violated. The authors concluded that individuals with AS have a sensory profile distinctive from neurotypical individuals and are apt to demonstrate disruptive behaviors when they encounter sensory problems.

\section{Motor Characteristics of Students With Asperger Syndrome}

Children with AS tend to have poor motor skills along with coordination and balance problems (Wing, 1981; Dunn et al., in press; Myles et al., 2000; Smith, 2000; Smith \& Bryson, 1994). The implications of these deficits are significant. First, being awkward and clumsy makes it difficult for students with AS to participate successfully in games requiring motor skills. Thus, their poor physical abilities and performance exacerbate their social deficits. Because participation in games and related activities is a primary social activity for children, problems in this area often go well beyond issues of motor coordination.

Second, fine-motor skill difficulties may complicate and interfere with a variety of school activities, such as handwriting, art, and industrial arts (Myles et al., 2000). Although some researchers dispute the presence of motor delays and aberrations in individuals with AS (Manjiviona \& Prior, 1995), sufficient evidence indicates that educators, at the very least, should be mindful of this being a potential problem.

\section{EFFECTIVE INTERVENTIONS}

School personnel must be in a position to provide appropriate and effective supports and accommodations to students with AS. In this connection, we offer recommended practices in the areas of social and behavioral supports, academic planning and programming, and sensory accommodations.

\section{Effective Social Interventions and Supports}

Children and youth with AS often have difficulty understanding social situations that can cause stress and anxiety (Barnhill, 2001a; Church, Alisanki, \& Amanullah, 2000; Myles, Barnhill, Hagiwara, Griswold, \& Simpson, 2001; Wing, 1991). Social situations that seem to be most problematic include:

1. Understanding facial expressions and gestures

2. Knowing how and when to use turn-taking skills, including focusing on the interests of others
3. Interpreting nonliteral language such as idioms and metaphors

4. Recognizing that others' intentions do not always match their verbalizations

5. Understanding the hidden curriculum-those complex social rules that often are not directly taught.

Even when a student with AS receives effective instruction in social skills, situations will arise that require interpretation. Unless interpreted, these situations become a source of stress and do not support future learning. With interpretation, however, perceptions of seemingly random actions can be altered into meaningful interactions for individuals with AS (Myles \& Simpson, 2001; Myles \& Southwick, 1999). Interpretive strategies include: (a) cartooning, (b) the Situation-Options-Consequences-Choices-StrategiesSimulation (SOCCSS) strategy, (c) social autopsies, (d) explaining the hidden curriculum, and (e) the Power Card.

\section{Cartooning}

The visual area seems to be a strength for individuals with AS (Dunn et al., in press; Rinner, 2000). Thus, visual systems may enhance the ability of children and youth with AS to understand their environment (Gray, 1995; Rogers \& Myles, 2001). One type of visual support is cartooning. This technique used generically has been implemented by speech/language pathologists for many years to enhance their clients understanding. Cartoon figures play an integral role in a number of other intervention techniques, including pragmaticism (Arwood, 1991), mind-reading (Howlin, Baron-Cohen, \& Hadwin, 1999) and comic strip conversations (Gray, 1995). Each of these techniques promotes social understanding by using simple figures and other symbols, such as conversation and thought bubbles, in a comic striplike format. This visual representation of a conversation helps individuals with AS analyze the social exchange (Myles \& Simpson, 2001a).

Although cartooning has limited scientific verification, some evidence suggests that learners with AS may be good candidates for social learning based on using a comic format to dissect and interpret social situations and interactions (Attwood, 1998; Howlin et al., 1999; Rogers \& Myles, 2001). Figure 1 provides a cartoon depicting a social interchange developed by Arwood and Brown (1999).

\section{Situation-Options-Consequences- \\ Choices-Strategies-Simulation}

Another interpretive technique, the Situation, Options, Consequences, Choices, Strategies, Simulation (SOCCSS) strategy, was developed to help students with social interaction problems put interpersonal relationships into a sequential form (J. Roosa, personal communication, June 4, 


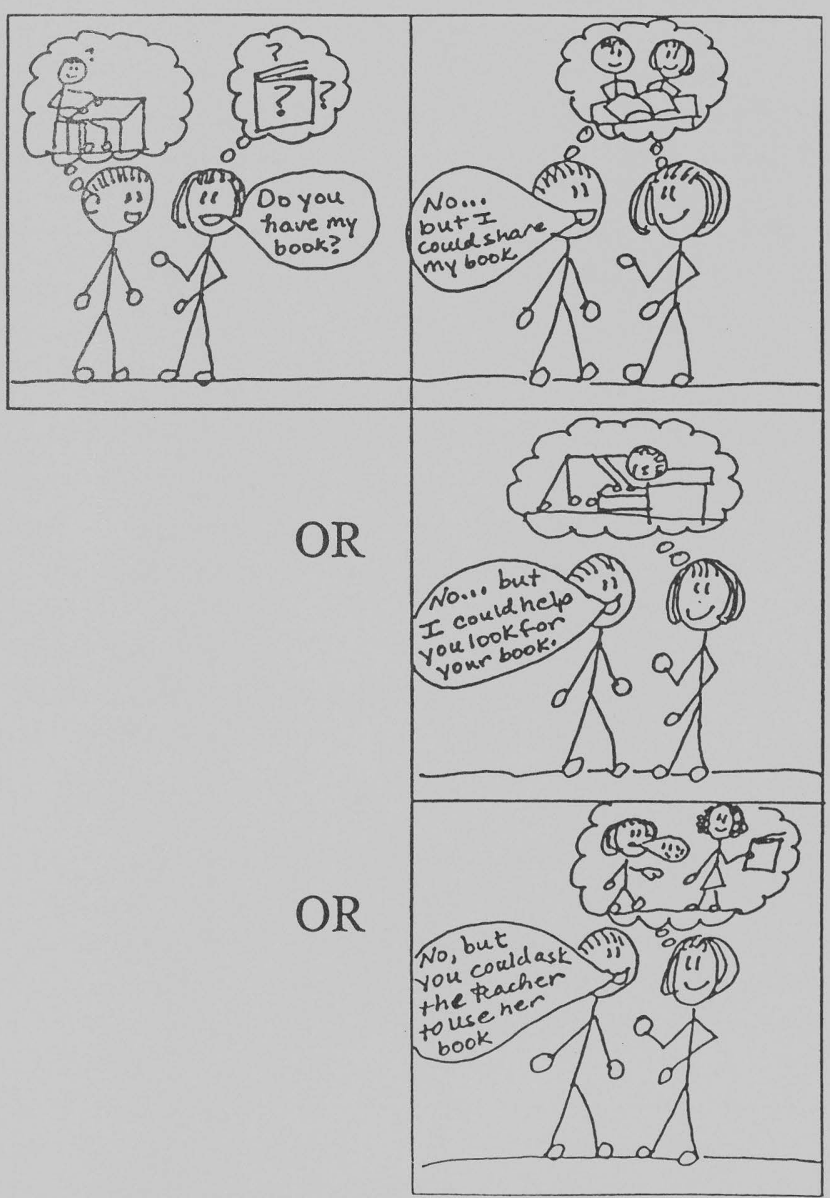

Source: A Guide to Cartooning and Flowcharting: See the Ideas, by E. L. Arwood \& M. M. Brown (Portland, OR: Apricot, Inc., 1999, p. 9). (C) Apricot, Inc. Used by permission.

FIGURE 1. Sample cartoon.

1997). It helps students understand problem situations and lets them see that they have to make choices about a given situation, with each choice having a consequence. The steps of SOCCSS are:

1. Situation. When a social problem arises, the teacher helps the student to understand the situation by first identifying (a) who was involved, (b) what happened, (c) the date, day, and time of occurrence, and (d) reasons for the present situation.

2. Options. The student, with the assistance of the teacher, brainstorms several options for behavior. At this point, the teacher accepts all student responses and does not evaluate them. This step encourages the student to see more than one perspective and to realize that any one situation presents several behavioral options.

3. Consequences. Then the student and teacher work together to evaluate each of the options generated. The teacher is a facilitator, helping the student to develop consequences for each option rather than dictating them.

4. Choices. The student selects the option or options that will have the most desirable consequences for him or her.

5. Strategy. Next the student and teacher develop an action plan to implement the selected option.

6. Simulation. Finally the student is given an opportunity to role-play the selected alternative. Simulation may be in the form of (a) role play, (b) visualization, (c) writing a plan, or (d) talking with a peer.

This strategy offers many benefits to the child or youth with AS. It allows students to (a) understand that many options may be available in any given situation, (b) realize that each option has a naturally occurring consequence, and (c) develop a sense of empowerment by acting on the environment (i.e., individuals with AS realize that they have choices, and by selecting one they can directly determine the consequences of their actions).

\section{Social Autopsies}

Richard LaVoie (cited in Bieber, 1994) developed social autopsies to help students with severe learning and social problems develop an understanding of social mistakes. An autopsy, in the traditional sense, is the examination and inspection of a dead body to discover the cause of death, determine damage, and prevent reccurrence. In this connection, social autopsy is an examination and inspection of a social error to discover the cause of the error, determine the damage, and prevent it from happening again. When a social mistake occurs, the student meets with an educator or caregiver to discuss it. Together, in a nonpunitive fashion, they identify the mistake. Then they discuss who was harmed by the error. The final step of the autopsy is to develop a plan to ensure that the error does not occur again (Myles \& Simpson, 2001b).

\section{Explaining the Hidden Curriculum}

The hidden curriculum refers to the set of routines, social rules, tasks, or actions that children, adolescents, and adults readily understand and use (Bieber, 1994). Often considered to be a matter of common sense, the hidden curriculum is almost never directly taught, yet it is a salient part of everyday life (Myles \& Simpson, 2001b; Myles \& Southwick, 1999). The hidden curriculum covers a multitude of areas. 
Thus, it is impossible to generate a comprehensive list that applies to all students with AS in all situations. The following is a brief list of hidden curriculum examples:

- Do not ask to be invited to someone's party.

- Do not tell classmates about all of the "skeletons in your parents' closets."

- Speak to teachers in a pleasant tone of voice because they will respond to you in a more positive manner. They also like it if you smile every once in a while.

- Do not correct someone's grammar when he or she is angry.

- Never break laws-no matter what your reason.

- When your teacher gives you a warning about your behavior and you continue the behavior, realize that you probably are going to get in trouble. If you stop the behavior immediately after the first warning, you will probably not get in trouble.

- Do not touch someone's hair even if you think it is pretty.

- Do not ask friends to do things that will get them in trouble.

- Understand that different teachers may have different rules for their classes.

- Do not draw violent scenes.

- Do not sit in a chair that someone else is sitting ineven if it is "your" chair.

- Do not argue with a policeman - even if you are right.

- Do not tell someone that his or her house is much dirtier than it should be.

- Do not tell someone you want to get to know better that he or she has bad breath.

- Do not try to do what actors do on television or the movies. These shows are not the same as real life.

- Do not pick flowers from someone's garden without permission, even if they are beautiful and you want to give them to someone.

\section{The Power Card}

The Power Card is a visual aid that helps children and youth with AS make sense of social situations, routines, the meaning of language, and the hidden curriculum (Gagnon, 2001). The Power Card uses children's special interest to help them make sense of a specific situation and motivates them to engage in a targeted behavior.

In using this intervention, an educator or parent develops a brief script written at the student's level of comprehension, detailing a problem situation or a target behavior and its relationship to the child's special interest. Power Cards also provide a solution, relying on the child's special interest. This solution then is generalized back to the child. A card the size of a business card or trading card, containing a picture of the special interest and a summary of the solution, can be carried with the student to promote generalization. The Power Card can be carried in a pocket, purse, or wallet, or it can be velcroed inside a book, notebook, or locker. It also may be placed on the corner of a child's desk (Gagnon, 2001). Figure 2 provides an example of a Power Card for a 14-year-old student who had problems with organizational skills. His special interest was Harvard.

\section{Behavioral Interventions and Supports for Students With Asperger Syndrome}

In addition to social interaction difficulties, many children and adolescents with AS are prone to behavior problems and, on occasion, aggression. As noted earlier, and reflected in the literature (Barnhill et al., 2000b; Frith, 1991), even though frequently motivated to be near to and to socially interact with peers and adults, students with AS are deficient in age-appropriate, reciprocal social interaction skills such as those required to participate in cooperative play and related activities.

A propensity for socially unacceptable behavior and insensitivity to or unawareness of verbal and nonverbal social cues makes these students vulnerable to displaying a variety of behavior problems. Accordingly, educators and families must provide appropriate instruction and supports for these children and adolescents to progress and experience success at school, at home, and in the community.

Behavior management options for students with AS are at the formative stage. That is, effective management practices still are being identified and debated. Hence, there are no clearly defined and generally agreed upon effective practices. Nevertheless, in this section we describe several

Remember these three things:

1. Take class notes and write down all assignments in your calendar.

\section{Ask questions when you don't understand.}

3. Break down assignments into small steps, assign deadlines for steps, and write all deadlines and due dates in your calendar.

Source: The Power Card: Using Special Interests to Motivate Children and Youth with Asperger Syndrome and Autism, by E. Gagnon (Shawnee Mission, KS: AAPC, 2001). Used with permission. 
methods that hold promise and that we have found to be potentially effective with children and youth diagnosed with AS

We strongly believe that the same basic management model that is used with other children and youth should also be applied when crafting management supports for students with AS. That is, teams of professionals and parents should cooperatively and prudently (a) target socially valid and pivotal responses for change; (b) ensure careful measurement of targeted responses selected for change; (c) systematically analyze behaviors that are identified for change relative to their functions and environmental and antecedent factors connected to their occurrence; and (d) select and systematically implement and evaluate appropriate interventions and treatments. Related to step (d), we discuss next several environmental supports and behavioral intervention options that we consider appropriate and potentially utilitarian for use with students who have AS.

\section{Environmental Structuring and Support}

A variety of strategies and methods are available to enhance the predictability of and benefits to be gained from the environmental setting. The security that comes from being able to anticipate and understand activities, schedules, and expectations significantly enhances AS students' capacity to appropriately respond to various classroom, home, and community demands. Establishing clear behavioral expectations and rules, following routines and schedules, and ensuring physical, environmental, cognitive, and attitudinal support are helpful in creating structure. In this connection, establishing and following clear behavioral expectations is one of the simplest, most effective, and most efficient means of establishing structure for students with AS.

Children with AS clearly benefit from environments that offer explicitly stated and modeled specification and examples of desired behaviors (Myles \& Simpson, 2001a). We also hasten to add that it is extremely important that these rules and expectations be reviewed regularly and that students have an opportunity to practice them in multiple settings and with multiple peers and adults.

Another simple and effective method of providing structure for students with AS is through routines and schedules. Building on their preference for predictability, order, and consistency, this structuring strategy assists children and youth with AS to respond and adapt more effectively to their ever-changing environment. Group and individual schedules, presented in written, pictorial, or combination formats, are especially useful in communicating the sequence of daily activities and in alerting children to new activities and schedule changes.

Physical, environmental, cognitive, and attitudinal support means making available adequate resources to effectively sustain, manage, and supervise students with AS in various settings, including classrooms and other school environments such as play areas and school buses, home settings, and community areas such as shopping malls. Paramount in providing these resources are adults and peers who are knowledgeable about and sensitive to students with AS and capable of supporting their needs.

On all too many occasions we have experienced situations in which peers have bullied and provoked students with AS to engage in unacceptable behaviors out of ignorance. Hence, a salient step in preparing supportive environments for students with AS is to inform their teachers and peers of the characteristics and nature of the disorder, their role in supporting students with the disability, and ensuring appropriate protection of these vulnerable children and adolescents.

\section{Behavioral Interventions}

Behavioral interventions entail manipulation of antecedent conditions such as curricula, instructional methods, and environments, as well as use of consequences for targeted behaviors. With regard to manipulation of consequences, it is important to recognize that many children and youth with AS do not respond well to typical "top-down" management strategies (Myles \& Simpson, 2001a). Approaches that seem to work best with these students give them an opportunity to participate in developing and implementing their own management systems. Whenever possible, then, we strongly recommend that children and youth with AS be involved in their own program development and implementation.

One specific behavioral technique that we have found to be useful with many students with AS is cognitive behavior modification (Meichenbaum, 1977). This is a technique that teaches individuals to monitor their own behavior or performance and to deliver self-reinforcement at established intervals. In this strategy, the locus of behavior control is shifted from an external source, such as a teacher or parent, to the student.

Cognitive behavior modification can be used to facilitate a variety of behavior changes, including following various specific classroom rules and attending to assigned classroom tasks. For example, one teenage boy diagnosed with AS was assisted in monitoring and changing his "stalking" behavior at school. The student had become a concern to school officials and his parents because of his serial interest in attractive female classmates (and one student teacher) in his school, none of whom he knew personally. His obsession with any one student typically lasted less than a week, but during this time he attempted to walk with these classmates from class to class, sit with them at lunch, and the like at every opportunity. Even though the young women protested loudly and did not encourage his interest in any way, it had 
no impact on his behavior. Moreover, negative consequences for this behavior, including suspension, only seemed to aggravate the problem.

The student, however, did respond positively to a cognitive behavior management program. His homeroom teacher and counselor used a videotaped sequence of his stalking behavior to assist him in understanding that his behavior was inappropriate. He then was (a) instructed to use a selfmonitoring system, structured by the school's bell system for signaling transitions; (b) taught to use a self-recording system related to his contact with other students; and (c) taught to use a self-reinforcement system. The reinforcement he selected was to spend time with peers who agreed to sit with him at lunch and walk with him during class transitions. Social skill instruction related to his behavior during these peer contacts also proved to be beneficial.

Finally, we consider it imperative that adults who work with students with AS recognize and plan for problems related to aggression and violence. These children and youth do not all have these problems, and individuals with AS are not inherently aggressive. Nevertheless, we must recognize that problems of aggression in some AS students do arise from time to time. The social deficits and excesses connected with AS, such as difficulty in engaging in age-appropriate reciprocal play, frequently create problems and frustrations that may escalate into aggressive responses and counter-actions. For example, a child with AS may have difficulty interacting with peers as a result of not understanding commonly known and accepted social rules, thereby giving the appearance of being rude or unwilling to follow generally understood game rules.

\section{Effective Academic Accommodations and Support Strategies}

Academic modifications essential for individuals with AS are those that increase structure and predictability and also address the multifaceted needs of this population (Attwood, 1998; Myles \& Adreon, 2001; Cumine, Leach, \& Stevenson, 1998). Specifically, these accommodations take into account some of the manifestations that are like learning disabilities (Griswold, Barnhill, Myles, Hagiwara, \& Simpson, in press; Gross, 1994; Happe, 1991; Myklebust, 1995) and gifted-like characteristics (Asperger, 1944; Wing, 1991) that are evident in children and youth with AS. Appropriate modifications include: (a) priming, (b) classroom assignment modifications, (c) notetaking, (d) graphic organizers, (e) enrichment, and (f) homework.

\section{Priming}

Wilde, Koegel, and Koegel (1992) devised priming to (a) familiarize children and youth with academic material prior to its use in school; (b) bring predictability to new tasks and thereby reduce stress and anxiety; and (c) increase the students' success. As discussed by Wilde and colleagues, the actual materials that will be used in a lesson are shown to the student the day, the evening, or even the morning before the activity is to take place. Priming also may occur just prior to an activity. A parent, paraprofessional, resource teacher, or trusted peer can serve as primers (Myles \& Adreon, 2001).

It is generally recommended that the actual teaching materials be used in priming. In some instances, however, priming can consist of introducing an upcoming task using a list or a description of the activities, not the actual materials. Priming is most effective when it is built into the student's routine. It should be done in an environment that is relaxing and should be facilitated by a primer who is both patient and encouraging. Finally, priming sessions should be short, providing a brief overview of the day's tasks in 10 to 15 minutes.

\section{Classroom Assignment Modifications}

The amount of reading the student with AS is expected to complete has to be evaluated. Students with AS-who sometimes read slowly and cannot discern relevant from irrelevant information - spend an inordinate amount of time concentrating on facts that will not be tested and are considered unimportant. Highlighted texts and study guides help these students maximize their reading time. Teachers also should consider identifying the information the student is responsible to learn for an upcoming assignment or test (Myles \& Adreon, 2001; Williams, 2001).

Handwriting is a concern for many children and youth with AS. Therefore, teachers must offer students several ways to demonstrate mastery, including (a) giving verbal responses instead of written essays; (b) using the computer instead of a pen or pencil; (c) completing a multiple-choice rather than a short-answer test, or (d) creating a project rather than writing a report.

\section{Notetaking}

Many students with AS have difficulty taking notes in class. Often, motor problems preclude their getting important content onto paper. In addition, some students have difficulty listening and writing at the same time. They can do both but often not at the same time. Depending on the amount of assistance they need, a teacher can provide for the student (a) a complete outline including the main idea and supporting details, (b) a skeletal outline that students can use to fill in details, (c) a peer-constructed outline, and (d) the opportunity to use outlining software (Myles \& Adreon, 2001).

\section{Graphic Organizers}

Graphic organizers highlight important concepts and display the relationship between them. They provide abstract or implicit information in a concrete manner. 
Graphic organizers can be used before, during, or after students read a selection-either as an advanced organizer or as a measure of concept attainment.

Three commonly used graphic organizers are semantic maps, analogy graphic organizers, and timelines. The focal point of the semantic map is the key word or concept enclosed in a geometric figure (e.g., circle or square) or in a pictorial representation of the word or concept. Lines or arrows connect this central shape to other shapes. Words or information related to the central concept are written on the connecting lines or in the other shapes. As the map expands, the words become more specific and detailed. For students who are young or who require additional cues, semantic maps can use pictures for the key words or concepts (Myles \& Simpson, 2001a).

An analogy graphic organizer contains two concepts and their attributes. The teacher and students define how the two concepts are alike and how they differ, then draw a conclusion. Often the teacher has to assist students in identifying attributes by presenting choices, either written or pictorial, from which the student can select. This task can be completed individually, in small groups, or with an entire class (Myles \& Simpson, 2001a).

Timelines provide benchmarks for completing tasks and thereby aid students in budgeting their time. Timelines consist of a list of steps needed to complete the task with concomitant due dates. This visual representation enables the student and teacher to monitor progress toward project completion. Ideally, teachers enlist the aid of parents in developing and monitoring timelines to ensure student followthrough at home.

\section{Enrichment}

Research has shown that a greater percentage of students with AS have IQs in the superior or very superior range than is found in the general population (Barnhill et al., 2000b). Thus, many children and youth with AS benefit from enrichment activities because they already have mastered ageappropriate academic content (Myles \& Adreon, 2001). Enrichment activities can consist of having students with AS learn the same content in much more depth and detail than their peers or introducing new topics that usually are presented to older students.

\section{Homework}

Teachers and parents or caregivers should work together to determine whether homework should be assigned and, if so, how much. Because students with AS need structure, it is often best for teachers to assign tasks that the student can complete in the structured school environment (Myles \& Simpson, 2001a).

If homework is assigned, an assignment notebook and a parent-teacher communication system will help parents or caregivers monitor the child's homework. In some cases, a parent may have to model the task for the student, so teachers should ensure that the parents or caregivers understand their child's homework. To facilitate home-school communication, some schools have established a "homework line" that students and parents can call to hear an overview of assigned work. This system is ideal for students with AS and their caregivers (Myles \& Simpson, 2001a).

\section{Sensory Issues}

As stated previously, sensory issues are replete in children and youth with AS (Church, Alisanki, Amanullah, 2000; Dunn et al., in press; Rinner, 2000). Similar to the social domain, addressing sensory issues requires looking beyond the behavior to interpret its reason before designing an intervention. As in all interventions, a team approach works best. Moreover, when dealing with sensory issues, an occupational therapist or other professional trained in sensory integration can be a valuable multidisciplinary team member (Myles et al., 2000).

Many of the interventions are easy to implement at school and home. Nevertheless, parents and educators should work together as a team to pinpoint the behavior a child exhibits (incident), its cause (interpretation), and practical solutions (intervention) (Dunn et al., in press; Myles et al., 2000).

\section{Programmatic Instruction}

A programmatic strategy for responding to sensory issues is often beneficial to children and youth with AS. One program, the visually based How Does. Your Engine Run: The Alert Program for Self-Regulation (Williams \& Shellenberger, 1996), seems particularly well-suited to the needs of these individuals (Myles et al., 2000). Williams and Shellenberger designed this program to help children and youth recognize their sensory needs. Specifically, How Does Your Engine Run helps students to recognize their level of alertness and compare it to task demands. If the two do not match, the child, after completing a series of lessons, is taught to adjust his or her arousal level to match task demands. To accomplish this, the authors grouped a variety of interventions into five categories: oral, movement, touch, visual, and aural. They designed this program for occupational therapists to use in conjunction with other educators and parents.

\section{Recommendations}

As any one behavior may have many sensory causes, it is difficult to set forth a series of universally applied recommendations that can be implemented at school and home. Intervention is effective when it directly addresses the function of the behavior. Be that as it may, Table 1 presents some common sensory issues, their causes, and intervention options. 


\section{TABLE 1}

\section{Sensory Issues of Individuals With Asperger Syndrome: Incidents, Interpretation, and Interventions}

\section{INCIDENT}

Has problem making eye contact with others

Doesn't seem to understand body language or facial expressions.

Has difficulty transitioning in hallways.

Hums constantly.

Has poor organizational skills; constantly loses school materials; papers fall out of notebook.

Has difficulty with change.

Touches everything.

Has messy handwriting.

Tantruming, screaming, or refusing to cooperate.

Has difficulty making friends.

INTERPRETATION

- Peripheral visual information may be more comfortable or useful than central vision.

- May have difficulty "looking" and "listening" at the same time.

- May have difficulty processing changes in body movements and facial expressions.

- May have problems distinguishing meaningful visual information from competing background detail.

- Awareness of others may be limited by preoccupation or focus.

- May fear being touched unexpectedly by somebody.

- Touch may be misinterpreted.

- Hall may be too loud.

- Visual activity may be disorienting.

- May be overstimulated by noise. The humming may block out noises that cause anxiety.

- Seeks auditory or tactile input.

- Has difficulty focusing on relevant stimuli.

- Has difficulty discriminating needed and unneeded items.

- Body does not feel in control when changes occur.

- Does not know what to do when change occurs.

- May learn through touching.

- May desire more tactile input.

- Does not receive the sensations to plan how to move and design a sequence of what comes next.

- Feel of the pencil may interfere with an effective pencil grasp.

- Situations that have loud echoes, noise, movement, and strong scents can be stressful.

- Stress and anxiety may dominate.

- May not know what to do.

- May not comprehend the meaning of gestures and facial expressions.

- Self-talk and other anxiety-reducing behaviors may interfere with interacting with others.

- Preoccupations may decrease awareness of social opportunities.
INTERVENTIONS

- Consider decreasing expectation of eye contact in some situations and contexts.

- Position in line of sight without getting too close.

- Provide minimal auditory or slight touch to encourage visual attention.

- Provide auditory cue to direct attention.

- Eliminate some of the background distractors.

- Accompany facial expressions, gestures, and body language with words.

- Be aware of the use of unspoken cues when delivering instruction.

- Allow the child to be first or last in line.

- Allow the child to leave class early.

- Have the child carry something heavy to provide proprioceptive input.

- If the noise or activity level is a concern, move the child away from the source of noise or activity.

- If the child needs to hum to concentrate, teach the child to hum more quietly.

- Provide visual structure through color-coding

- Use tape inside the desk as a boundary marker for books.

- Offer a signal before a change occurs.

- Use visual supports to prepare the child for changes.

- Provide deep pressure activities that the child may utilize.

- Give the child a script to use when an unexpected event occurs.

- Before the child enters the environment in which many items are not to be touched, provide deep pressure by rubbing shoulders, back, or palms.

- Accompany a touch by a verbal statement of the rules for touching.

- Have the child engage in gross-motor activities before being asked to perform fine-motor activities.

- Encourage the child to participate in activities that develop hand strength.

- Have the child write on raised-line paper.

- Teach keyboarding skills.

- Decrease stress and anxiety through visual supports, structure, and predictability.

- Modify environment to meet student needs.

- Provide a home base.

- Establish structured activities with preassigned roles that can be practiced.

- Teach the child how to approach an individual or group, as well as the skills needed to interact with peers.

- Structure social activities around special interests. 


\section{CONCLUSION}

Only recently has AS been showing up on the educational "radar screen," and ever-increasing numbers of children and youth are being identified with the disorder. Moreover-and arguably just as important as the increased prevalence of the disability-teachers, administrators, counselors, and other educational professionals are quickly discovering the challenge of serving children and youth with AS effectively. One principal with whom we have contact observed that "these kids [with AS] are very, very high-maintenance." That they generally will spend most of their educational hours in general education settings further accentuates the challenge they present. That is, their presence in general education means that professionals who do not ordinarily have specialized training for students with disabilities will be their teachers for the most part. Further, their placements in general classrooms means that they will share space and experiences with normally developing and achieving classmate who can be expected to have limited tolerance (at least without instruction and other interventions) for peers who fail to understand and follow the often complex and frequently unstated rules of their classroom and school.

Educational and noneducational professionals alike are struggling to understand the nature and unique qualities of AS (Church et al., 2000; Klin et al., 2000; Myles \& Simpson, 2001a). Indeed, myriad unanswered questions related to the nature and characteristics of the disorder daily confront professionals and parents who must diagnose, teach, raise, and otherwise support children and youth identified as having AS.

Educators, parents, and other professionals must accept that we currently lack a clear and definitive description of methods and strategies whose use bodes best for children and youth with AS. At the same time, we are encouraged by the ever-increasing flow of information related to accommodations, supports, methods, and interventions that can be applied to meet the needs of these students.

The same principal who reminded us of the "high maintenance" of students with AS also observed that his staff was getting much better at providing them a safe, productive, and high-quality educational experience. In spite of the lack of clear consensus on effective practices, a number of potentially useful steps and strategies are available to educators and other professionals who work with children and adolescents with AS.

We recognize that increased availability of methods and strategies for students with AS is no assurance that educators and other professionals will be aware of and effectively use these options. At the same time, however, we accept that we are making significant progress by taking this important first step. Professionals and parents must realize that there will not be a single effective practice for all children and youth with AS. Individuals with this complex disorder seem to have needs that can be addressed effectively only when trained professionals correctly use a variety of appropriate methods in an individualized fashion. That these methods must address multiple domains related to AS-social, behavioral, academic, motor, and sensory-across school, home, and community settings, is very clear.

We optimistically conclude by observing that we have received much inspiration and encouragement from the excitement and progress of the students with whom we have used the strategies and accommodations discussed in this article. Students with AS often appear (and frequently confess) to being overwhelmed, stressed, and frustrated by a complex and dynamic world in which they struggle to understand and be a productive part. In this context, many of these students embrace and enthusiastically use those techniques that functionally assist them in understanding and structuring their perceptions, perspectives, and behavior to fit the demands of their world.

\section{REFERENCES}

American Psychiatric Association. (1994). Diagnostic and statistical manual of mental disorders (4th ed.). Washington, DC: Author.

American Psychiatric Association. (2000). Diagnostic and statistical manual of mental disorders (4th ed., text revision). Washington, DC: Author.

Arwood, E. L. (1991). Semantic and pragmatic language disorders (2d ed.). Denver: Aspen.

Arwood, E. L., \& Brown, M. M. (1999). A guide to cartooning and flowcharting: See the ideas. Portland, OR: Apricot, Inc.

Asperger, H. (1944). Die 'autistischen psychopathen' im kindesalter. Archiv fur Psychiatrie und Nervenkrankheiten, 117, 76-136.

Attwood, T. (1998). Asperger's syndrome: A guide for parents and professionals. London: Jessica Kingsley.

Barnhill, G. P. (2001a). Social attribution and depression in adolescents with Asperger Syndrome. Focus on Autism \& Other Developmental Disabilities, 16, 46-53.

Barnhill, G. (2001b). What is Asperger syndrome? Intervention in School \& Clinic, 36, 259-265.

Barnhill, G., Hagiwara, R., Myles, B. S., \& Simpson, R. L. (2000a). Asperger syndrome: A study of the cognitive profiles of 37 children and adolescents. Focus on Autism \& Other Developmental Disabilities, 15, 146-153.

Barnhill, G. P., Hagiwara, R., Myles, B. S., Simpson, R. L., Brick, M. L., \& Griswold, D. E. (2000b). Parent, teacher, and self-report of problem and adaptive behaviors in children and adolescents with Asperger syndrome, Diagnostique, 25, 147-167.

Bieber, J. (Producer). (1994). Learning disabilities and social skills with Richard LaVoie: Last one picked . . . first one picked on. Washington, DC: Public Broadcasting Service.

Cesaroni, L., \& Garber, M. (1991). Exploring the experience of autism through firsthand accounts. Journal of Autism \& Developmental Disorders, 21, 303-313.

Church, C., Alisanki, S., \& Amanullah, S. (2000). The social, behavioral, and academic experiences of children with Asperger syndrome. Focus on Autism \& Other Developmental Disabilities, 15, 12-20. 
Cumine, V., Leach, J., \& Stevenson, G. (1998). Asperger syndrome: A practical guide for teachers. London: David Fulton.

Dunn, W., Myles, B. S., \& Orr, S. (in press). Sensory processing issues associated with Asperger syndrome: A preliminary investigation. American Journal of Occupational Therapy.

Ehlers, S., \& Gillberg, C. (1993). The epidemiology of Asperger syndrome: A total population study. Journal of Child Psychology and Psychiatry, 34, 1327-1350.

Ehlers, S., Nyden, A., Gillberg, C., Sandberg, A. D., Dahlgren, S., Hjelmquist, E., \& Odom, A. (1997). Asperger Syndrome, autism, and attention deficit disorders: A comparative study of the cognitive profiles of 120 children. Journal of Child Psychology and Psychiatry \& Allied Disciplines, 38. 207-217.

Frith, U. (1991). Autism and Asperger syndrome. Cambridge, UK: Cambridge University Press.

Gagnon, E. (2001). The Power Card: Using special interests to motivate children and youth with Asperger syndrome and autism. Shawnee Mission, KS: AAPC.

Gagnon, E., \& Myles, B. S. (1999). This is Asperger syndrome. Shawnee Mission, KS: Autism Asperger Publishing.

Ghaziuddin, M., Weidmer-Mikhail, E., \& Ghaziuddin, N. (1998). Comorbidity of Asperger syndrome: A preliminary report. Journal of Intellectual Disability Research, 42, 279-283.

Gray, C. (1995). Social stories unlimited: Social stories and comic strip conversations. Jenison, MI: Jenison Public Schools.

Griswold, Barnhill, Myles, Hagiwara, and Simpson (in press). Asperger syndrome and academic achievement. Focus on Autism and Other Developmental Disabilities.

Gross, J. (1994). Asperger syndrome: A label worth having? Educational Psychology in Practice, 10, 104-110.

Happe, F. G. (1991) The autobiographical writings of three Asperger syndrome adults: Problems of interpretation and implications for theory. In U. Frith (Ed.), Autism and Asperger syndrome (pp. 207-242). Cambridge, MA: Cambridge University Press.

Howlin, P., Baron-Cohen, S., \& Hadwin, J. (1999). Teaching children with autism to mind-read: A practical guide. New York: John Wiley \& Sons.

Kadesjo, B., Gillberg, C., \& Nagberg, B. (1999). Autism and Asperger syndrome in seven-year-old children: A total population study. Journal of Autism \& Developmental Disorders, 29, 327-332.

Klin, A., Volkmar, F., \& Sparrow, S. (2000). Asperger syndrome. New York: Guilford Press.

Koning, C., \& McGill-Evans, J. (2001). Social and language skills in adolescent boys with Asperger syndrome. Autism: The International Journal of Research \& Practice, 5, 23-36.

Lincoln, A., Courchesne, E., Kilman, B., Elmasian, R., \& Allen, M. (1988). A study of intellectual abilities in high-functioning people with autism. Journal of Autism \& Developmental Disabilities, 18, 505-524.

Manjiviona, J., \& Prior, M. (1995). Comparison of Asperger syndrome and high-functioning autistic children on a test of motor impairment. Journal of Autism \& Developmental Disorders, 25, 23-39.

Meichenbaum, (1977). Cognitive behavior modification: An integrative approach. New York: Plenum.

Myklebust, H. R. (1995). Verbal and nonverbal cognitive processes: A comparison of learning disability and autistic children. In E. Schopler \& G. B. Mesibov (Eds.), Learning and cognition in autism (pp. 33-53). New York: Plenum Press.
Myles, B. S., \& Adreon, D. (2001). Asperger syndrome and adolescence: Practical solutions for school success. Shawnee Mission, KS: AAPC.

Myles, B. S., Barnhill, G. P., Hagiwara, T., Griswold, D. E., Simpson, R. L. (2001). A synthesis of studies on the intellectual, academic social/emotional and sensory characteristics of children and youth with Asperger syndrome. Education \& Training in Mental Retardation and Developmental Disabilities, 36(3), 304-311.

Myles, B. S., Cook, K. T., Miller, N. E., Rinner, L., \& Robbins, L. A. (2000). Asperger syndrome and sensory issues: Practical solutions for making sense of the world. Shawnee Mission, KS: AAPC

Myles, B. S., \& Simpson, R. L. (2001a). Asperger syndrome: A guide for educators and parents (2nd ed.). Austin, TX: Pro-Ed.

Myles, B. S., \& Simpson, R. L. (2000b). Understanding the hidden curriculum: An essential social skill for children and youth with Asperger Syndrome. Intervention in School \& Clinic 36, 279-286.

Myles, B. S., \& Southwick, J. (1999). Asperger syndrome and difficult moments: Practical solutions for tantrums, rage, and meltdowns. Shawnee Mission, KS: Autism Asperger Publishing.

Rinner, L. (2000). Asperger syndrome and autism: Comparing sensory processing in daily life. Unpublished master's thesis, University of Kansas, Lawrence.

Rogers, M. F., \& Myles, B. S. (2001). Using social stories and comic strip conversations to interpret social situations for an adolescent with Asperger syndrome. Intervention in School \& Clinic, 36, 310-313.

Siegel, D., Minshew, N., \& Goldstein, G. (1996). Weschler IQ profiles in diagnosis of high-functioning autism. Journal of Autism \& Developmental Disorders, 26, 389-406.

Smith, I. (2000). Motor functioning in Asperger syndrome. In A. Klin, F. Volkmar, \& S. Sparrow (Eds.), Asperger syndrome (pp. 97-124). New York: Guilford Press.

Smith, I., \& Bryson, S. (1994). Imitation and action in autism: A critical review. Psychological Bulletin, 116, 259-273.

Szatmari, P. (1991). Asperger's syndrome: Diagnosis, treatment, and outcome. Pediatric Clinics of North America, 14(1), 81-92.

Volkmar, F., \& Klin, A. (2000). Diagnostic issues. In A. Klin, F. Volkmar, \& S. Sparrow (Eds.), Asperger syndrome (pp. 25-71). New York: Guilford Press.

Wechsler, D. (1989). Wechsler preschool and primary scale of intelligence-Revised. New York: Psychological Corp.

Wechsler, D. (1991). Wechsler intelligence scale for children-Third edition. New York: Psychological Corp.

Wilde, L. D., Koegel, L. K., \& Koegel, R. L. (1992). Increasing success in school through priming: A training manual. Santa Barbara: University of California.

Williams, K. (2001). Understanding the student with Asperger syndrome: Guidelines for teachers. Intervention in School \& Clinic, 36, 287-292.

Williams, M. W., \& Shellenberger, S. (1996). How does your engine run? A leader's guide to the Alert program for self-regulation. Albuquerque, NM: Therapy Works.

Wing, L. (1981). Asperger syndrome: A clinical account. Psychological Medicine, 11, 115-129.

Wing, L. (1991). The relationship between Asperger's syndrome and Kanner's autism. In U. Frith (Ed.) Autism and Asperger Syndrome (pp. 93-121). Cambridge, MA: Cambridge University Press. 


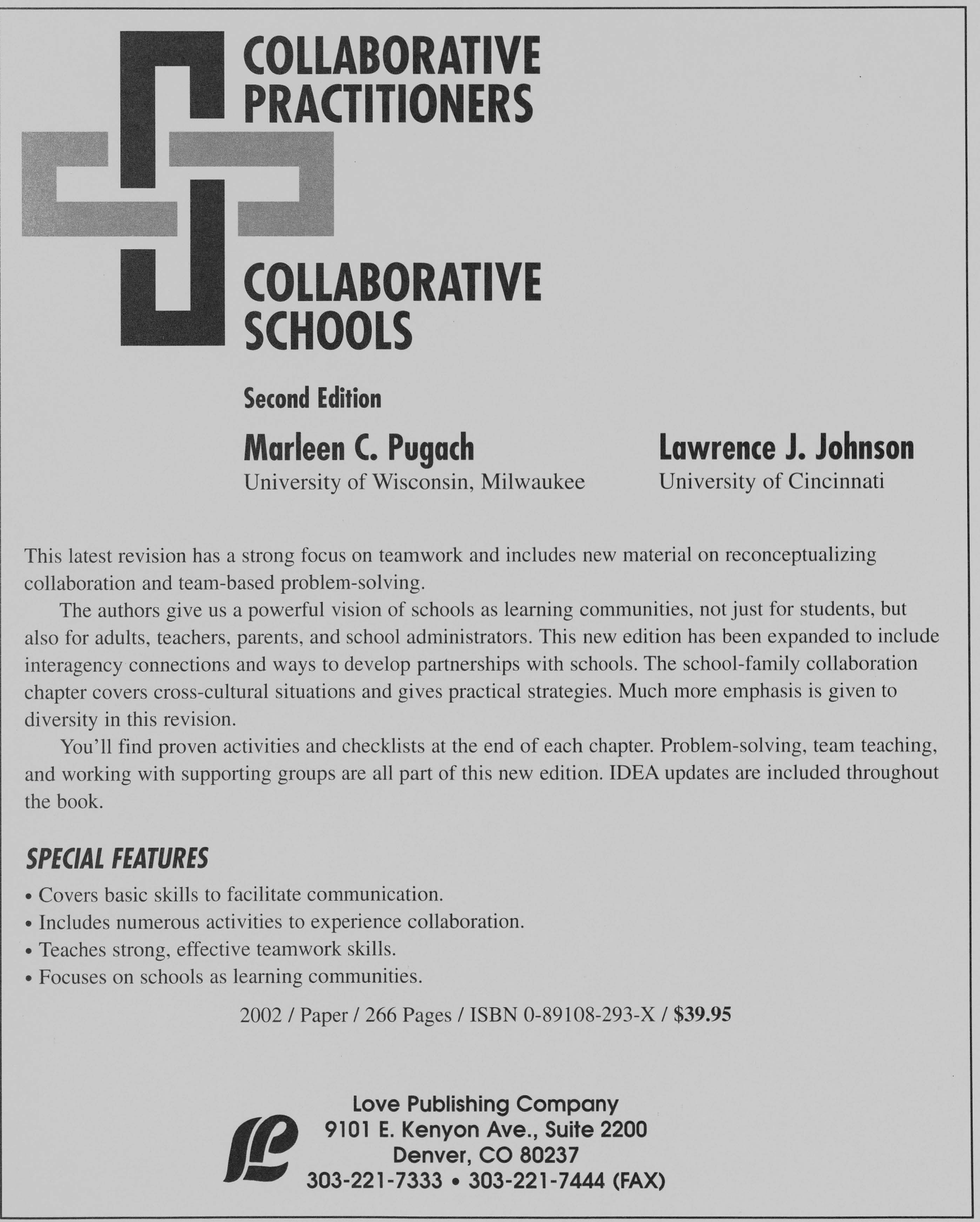




\section{Professional update}

Learning Disabilities Association of America International Conference

February 13-16, 2002

Denver, Colorado

Contact: LDA 4156 Library Road Pittsburgh, PA 15234

\section{Midwest Symposium for Leadership Behavior Disorders}

February 21-22, 2002

Hyatt Regency-Crown Center

Kansas City, Missouri

Contact: 913-492-8755 Fax: 913-492-2546

\section{Council for Exceptional Children}

April 3-6, 2002

New York, New York

Contact: www.cec.sped.org 800-486-5773

\section{American Educational Research Association}

April 1-5, 2002

New Orleans, Louisiana

Contact: www.aera.net 202-223-9485 